\title{
Advancing Neuroanesthesia and Neurocritical Care during the COVID-19 Pandemic and Infodemic: Focus on Education, Innovation, and Collaboration
}

\author{
Deepak Sharma ${ }^{1}$ \\ ${ }^{1}$ Division of Neuroanesthesiology and Perioperative Neurosciences, \\ Department of Anesthesiology and Pain Medicine, \\ University of Washington, Seattle, Washington, United States
}

J Neuroanaesthesiol Crit Care 2020;7:52-53

The current coronavirus disease (COVID-19) pandemic has impacted medicine, healthcare, science, and society in unprecedented ways. ${ }^{1}$ Anesthesiologists are at the forefront of the global battle against this pandemic in their roles as acute care specialists and intensivists in addition to continuing to provide anesthesia care. While the entire field of medicine has gone above and beyond in responding to the pandemic, anesthesiologists, in particular, have unique skill set that makes them extremely valuable in managing critically ill COVID-19 patients.

Relevant to neuroanesthesiology and neurocritical care, neurological manifestations have been reported in over a third of the hospitalized patients with COVID-19 from Wuhan, China. ${ }^{2}$ Observations from France report neurologic findings in $14 \%$ patients on admission to the intensive care unit and in $67 \%$ subsequently when sedation and neuromuscular blocker were withheld. ${ }^{3}$ Patients with severe COVID-19 appear to be more likely to manifest acute cerebrovascular diseases, consciousness impairment, and skeletal muscle symptoms. ${ }^{2}$ There are growing concerns about acute cerebrovascular disease, particularly ischemic stroke, in the spectrum of thrombotic complications in critically ill patients with COVID-19. ${ }^{4} \mathrm{~A}$ high incidence of cerebral hypoperfusion has also been reported among patients who underwent perfusion imaging. ${ }^{3}$ These findings have significant implications for neuroanesthesia and critical care practice. However, given the pandemic situation, the clinical care of patients without the severe acute respiratory syndrome-coronavirus 2 (SARS-CoV-2) infection also requires special considerations to optimize patient outcomes. Moreover, ensuring safety of healthcare personnel and optimal resource utilization are essential. Limited availability of data despite the urgent need of clinical guidance has led to the development of consensus recommendations and guidelines. Given the circumstantial limitations, such guidance is usually based on limited data, translation of evidence from other relevant situations, and collective wisdom. ${ }^{5,6}$ The Society for Neuroscience in Anesthesiology and Critical Care (SNACC) has developed consensus recommendations for neuroanesthesia practice during COVID-19. ${ }^{7.8}$ Nevertheless, it is imperative that efforts be made to conduct research and collect data from larger patient populations to further inform clinical care. Research priorities for perioperative neuroscience should include (1) detailed description of neurological manifestations and complications of COVID-19, (2) discovering their risk factors and mechanisms, (3) identifying optimal management/ prevention strategies and drug choices to optimize neurological outcomes, (4) examining the impact of anesthetic techniques/agents on neurological outcomes, and (5) identifying effective interventions to limit the burden of disease and protecting healthcare personnel.

Beyond direct clinical care, the pandemic has impacted medicine in several other domains encompassing education, training, and research. Cancellation of elective surgeries and significantly reduced opportunities for supervised clinical training due to limited availability of personal protective equipment (PPE) in addition to cancellation of didactic and simulation teaching have led to concerns about adverse impact on trainee education. ${ }^{9}$ While research on COVID-19 is rightly considered essential and high priority during the ongoing pandemic, the emphasis has inadvertently had a negative impact on research that is not directly related to COVID-19 especially due to the associated economic downturn. ${ }^{10}$ The economic and social impact of the pandemic is likewise profound. ${ }^{11}$ Despite the adversity, the scientific and medicine community has demonstrated exceptional solidarity. The challenges posed

(C)2020 Indian Society of

Neuroanaesthesiology and Critical Care
DOI https://doi.org/

10.1055/s-0040-1713018 ISSN 2348-0548.

\section{License terms}

()ㅜ (1) $\Theta$ 
by the pandemic have motivated innovation and collaboration in clinical practice as well as educational methods. While effective telemedicine and telehealth programs cannot be created de novo during a short period, health systems that have already implemented telemedical innovations have been able to leverage them for the response to COVID-19.12,13 Concurrently, relatively low-cost and easy access social media tools are being explored as means of telemedicine in resource-limited settings. ${ }^{14}$ Similarly, efforts are being made to provide medical education using innovative solutions including the flipped classroom model, online practice questions, teleconferencing, and facilitated use of procedural videos. ${ }^{15}$ The impact of such innovations and adaptive changes on clinical and educational outcomes will be of interest to the specialty. Not surprising, hospitals and healthcare systems have recognized the importance of greater emphasis on infection control measures, which are likely to be a long-term focus now. New research into effectiveness of perioperative infection-control strategies is anticipated.

The ongoing pandemic has posed unique challenges for scientific societies and journals also. Some of these challenges relate to the cancelled conferences, workshops, and symposia coupled with potentially compromised academic output, reduced availability of new research findings as well as relatively limited availability of expert reviewers. It is also anticipated that journals will receive a large number of manuscripts related to COVID-19 for possible publication that will require expedited review, decision, and publication if deemed suitable..$^{16}$ This creates additional demand on resources. Nevertheless, scientific journals have a tremendous responsibility in helping combat the infodemic by appropriately filtering reliable research and educational work for publication and dissemination. ${ }^{17}$ In fact, timely publication of relevant, high-quality, peer-reviewed articles is considered a social responsibility of medical journals. ${ }^{18}$ This edition of the Journal of Neuroanaesthesiology and Critical Care (JNACC) includes two narrative reviews and a commentary related to COVID-19.6,19,20 As new data emerges, we will continue to learn more about COVID-19 and its neurological implications.

\section{Conflict of Interest}

The author is an Editorial Board Member of Journal of Neuroanaesthesiology and Critical Care (JNACC). He is also the President of Society of Neuroscience in Anesthesiology and Critical Care (SNACC) and serves on the editorial board of the Journal of Neurosurgical Anesthesiology.

\section{References}

1 Zhang SX, Wang Y, Rauch A, Wei F. Unprecedented disruption of lives and work: health, distress and life satisfaction of working adults in China one month into the COVID-19 outbreak. Psychiatry Res 2020. Doi: 10.1016/j.psychres.2020.112958

2 Mao L, Jin H, Wang M, et al. Neurologic manifestations of hospitalized patients with coronavirus disease 2019 in Wuhan, China. JAMA Neurol 2020. Doi: 10.1001/jamaneurol.2020.1127

3 Helms J, Kremer S, Merdji H, et al. Neurologic features in severe SARS-CoV-2 infection. N Engl J Med 2020. Doi: 10.1056/ NEJMc2008597
4 Klok FA, Kruip MJHA, van der Meer NJM, et al. Incidence of thrombotic complications in critically ill ICU patients with COVID-19. Thromb Res 2020. Doi: 10.1016/ j.thromres.2020.04.013

5 Moppett IK, Gardiner D, Harvey DJR. Guidance in an uncertain world. Br J Anaesth 2020. Doi: 10.1016/j.bja.2020.04.003

6 Alessandri F, Bilotta F, Ceccarelli G, et al. Clinical management of critical Covid-19 patients: insights from the literature and "on the field" experience. J Neuroanesthesiol Crit Care 2020;7(2):54-61

7 Sharma D, Rasmussen M, Han R, et al. Anesthetic Management of Endovascular Treatment of Acute Ischemic Stroke During COVID-19 Pandemic: Consensus Statement from Society for Neuroscience in Anesthesiology \& Critical Care (SNACC)_Endorsed by Society of Vascular \& Interventional Neurology (SVIN), Society of NeuroInterventional Surgery (SNIS), Neurocritical Care Society (NCS), and European Society of Minimally Invasive Neurological Therapy (ESMINT). J Neurosurg Anesthesiol 2020. Doi: 10.1097/ ANA.0000000000000688

8 Flexman AM, Abcejo A, Avitisian R, et al. Neuroanesthesia practice during the COVID-19 pandemic: recommendations from Society for Neuroscience in Anesthesiology \& Critical Care (SNACC). J Neurosurg Anesthesiol 2020. Doi: 10.1097/ ANA.0000000000000691

9 Bambakidis NC, Tomei KL. Editorial. Impact of COVID-19 on neurosurgery resident training and education. J Neurosurg 2020. Doi: 10.3171/2020.3.JNS20965

10 Yanow SK, Good MF. Nonessential research in the new normal: the impact of novel coronavirus disease (COVID-19). Am J Trop Med Hyg 2020. Doi: 10.4269/ajtmh.20-0325

11 Kickbusch I, Leung GM, Bhutta ZA, Matsoso MP, Ihekweazu C, Abbasi K. Covid-19: how a virus is turning the world upside down. BMJ 2020;3:369:m133

12 Hollander JE, Carr BG. Virtually perfect? Telemedicine for Covid-19. N Engl J Med 2020;382(18):1679-1681

13 Eccleston C, Blyth FM, Dear BF, et al. Managing patients with chronic pain during the COVID-19 outbreak: considerations for the rapid introduction of remotely supported (eHealth) pain management services. Pain 2020;161(5):889-893

14 Jakhar D, Kaul S, Kaur I. WhatsApp messenger as a teledermatology tool during coronavirus disease (COVID-19): from bedside to phone-side. Clin Exp Dermatol 2020. Doi: 10.1111/ ced. 14227

15 Chick RC, Clifton GT, Peace KM, et al. Using technology to maintain the education of residents during the COVID-19 pandemic. J Surg Educ 2020. Doi: 10.1016/j.jsurg.2020.03.018

16 Cannistra SA, Haffty BG, Ballman K. Challenges faced by medical journals during the COVID-19 pandemic. J Clin Oncol 2020. Doi: $10.1200 / J C O .20 .00858$

17 Orso D, Federici N, Copetti R, Vetrugno L, Bove T. Infodemic and the spread of fake news in the COVID-19-era. Eur J Emerg Med 2020. Doi: 10.1097/MEJ.0000000000000713

18 Hamid ARAH. Social responsibility of medical journal: a concern for COVID-19 pandemic. Med J Indones [Internet]. 2020;29(1):1-. Available at: http://mji.ui.ac.id/journal/index. $\mathrm{php} / \mathrm{mji} /$ article/view/4629. Accessed March 2020

19 Sarkar S, Khanna P, Dube SK. Spectrum of neurological complications in COVID-19: an evidence-based review. J Neuroanesthesiol Crit Care 2020;20(2):xx-xx

20 Jangra K, Paliwal S, Tripathi M. COVID-19 and neurosurgery: time for triage. J Neuroanesthesiol Crit Care 2020;7(2):67-79 